\title{
Environmental footprint of regular and intensive inpatient care in a large US hospital
}

\author{
Purnima Aishwarya Prasad ${ }^{1} \cdot$ Dhruvi Joshi $^{2} \cdot$ Jennifer Lighter ${ }^{3} \cdot$ Jenna Agins ${ }^{4} \cdot$ Robin Allen $^{5} \cdot$ Michael Collins $^{6}$. \\ Foohel Pena ${ }^{5}$. Joan Velletri ${ }^{5}$. Cassandra Thiel ${ }^{7}$ (i)
}

Received: 20 January 2021 / Accepted: 9 November 2021 / Published online: 4 December 2021

(c) The Author(s) 2021

\begin{abstract}
Purpose Environmental sustainability is a growing concern to healthcare providers, given the health impacts of climate change and air pollution, and the sizable footprint of healthcare delivery itself. Though many studies have focused on environmental footprints of operating rooms, few have quantified emissions from inpatient stays. This study quantifies solid waste and greenhouse gas emissions (GHGs) per bed-day in a regular inpatient (low intensity) and intensive care unit (high intensity). Methods This study uses hybrid environmental life cycle assessment (LCA) to quantify average emissions associated with resource use in an acute inpatient unit with 49 beds and 14,427 hospitalization days and an intensive care unit (ICU) with 12 beds and 2536 hospitalization days. The units are located in a single tertiary, private hospital in Brooklyn, NY, USA. Results and discussion An acute care unit generates $5.5 \mathrm{~kg}$ of solid waste and $45 \mathrm{~kg} \mathrm{CO}_{2}$-e per hospitalization day. The ICU generates $7.1 \mathrm{~kg}$ of solid waste and $138 \mathrm{~kg} \mathrm{CO}_{2}$-e per bed day. Most emissions originate from purchase of consumable goods, building energy consumption, purchase of capital equipment, food services, and staff travel.

Conclusions The ICU generates more solid waste and GHGs per bed day than the acute care unit. With resource use and emission data, sustainability strategies can be effectively targeted and tested. Medical device and supply manufacturers should also aim to minimize direct solid waste generation.
\end{abstract}

Keywords Healthcare $\cdot$ Inpatient $\cdot$ Internal medicine $\cdot$ Waste $\cdot$ Life cycle assessment $\cdot$ Sustainability $\cdot$ Greenhouse gas emissions (GHGs)

Communicated by Yi Yang.

Cassandra Thiel

cassandra.thiel@nyulangone.org

Purnima Aishwarya Prasad

pap391@nyu.edu

Dhruvi Joshi

dsj268@nyu.edu

Jennifer Lighter

Jennifer.Lighter@nyulangone.org

Jenna Agins

Jenna.Agins@nyulangone.org

Robin Allen

Robin.Allen@nyulangone.org

Michael Collins

Michael.Collins@erm.com

Foohel Pena

Foohel.Pena@nyulangone.org

Joan Velletri

Joan.Velletri@nyulangone.org
1 NYU Tandon, 227 E. 30th St. Sixth Floor, New York, NY 10016, USA

2 NYU Abu Dhabi, Saadiyat Island, PO Box 129188, Abu Dhabi, UAE

3 Department of Pediatrics, NYU Langone Health, New York, NY 10016, USA

4 NYU Langone Health, 545 First Avenue, Greenberg Hall, SC2-122, New York, NY 10016, USA

5 NYU Langone Hospital-Brooklyn, 150 55th St, Brooklyn, NY 11220, USA

6 Environmental Resources Management Ltd., 2nd Floor Exchequer Court 33rd St Mary Axe, London EC3A 8AA, UK

7 NYU Langone Health, 227 E. 30th St. \#636, New York, NY 10016, USA 
The cost of healthcare in the United States (US) is the highest in the world, while the US ranks lower than other developed countries for health outcomes (CMS 2017). Improving the value of US healthcare requires us to reflect on the resources we consume in delivering care (Thiel and Horwitz 2019). In addition to the financial costs, healthcare's resource use degrades the environment and, with it, public health (Eckelman and Sherman 2018; Salas et al. 2020; Costello wt al. 2013; Berrang-Ford et al. 2021). The healthcare industry is responsible for $8.5 \%$ of domestic US greenhouse gas emissions (GHGs), the highest value per capita for any country (Eckelman et al. 2020), which directly impacts the health of patients. Despite an increased desire to improve sustainability in healthcare, the sector has been slow to adopt sustainable practices and policies, in part due to lack of research identifying appropriate interventions (Sherman et al. 2020, 2019).

An increasing number of life cycle assessment (LCA) and carbon footprinting studies are being conducted in the healthcare sector, given its sizable impact on emissions (Karliner et al. 2019; Cimprich et al. 2019). Prior healthcare LCA studies have focused on comparing reusable and disposable medical equipment such as laryngoscopes, laryngeal mask airways, and dental burs, often showing that reusable medical equipment has lower environmental impacts (Sherman and Eckelman 2018; Unger and Landis 2014; Eckelman et al. 2012). Researchers have also conducted LCAs for specific medical procedures such as childbirth (Campion et al. 2012), hysterectomy (Thiel et al. 2018, 2014; Power et al. 2012), eye surgeries (Thiel et al. 2017; Tauber et al. 2019), plastic and other surgeries (Berner et al. 2017; MacNeill et al. 2017), dialysis (Piccoli and Mery 2017; Barraclough et al. 2017; Chen et al. 2016; Lim et al. 2013; Connor et al. 2011), radiology (Martin et al. 2018; Chua et al. 2021), and pathology (Gordon et al. 2021). Studies at this level often report the largest share of emissions coming from single use and disposable supply production as well as energy use, though LCAs in low-resource setting often show more efficient resource utilization and variance in sources of emissions (Goel et al. 2021; Steyn et al. 2020). Emissions for other aspects of healthcare have also been studied, including anesthesia (Sherman et al. 2012; Andersen et al. 2012), telemedicine (Holmner et al. 2014), pharmaceuticals, and asthma treatment (Janson et al. 2020; Belkhir and Elmeligi 2019). Many healthcare-based studies indicate that material use and emissions within the healthcare sector can be reduced without sacrificing safety or efficacy (Sherman et al. 2020). Despite this growth in understanding the sources of emissions in the healthcare sector, few studies have analyzed the footprint of inpatient units in the US (McGain et al. 2018).

As of 2014, there were approximately 36 million inpatient stays in the US, with an average length of a patient stay of 5.5 days (Development 2019; McDermott et al. 2017). More resource-intensive stays in intensive care units (ICUs) account for about 5.7 million inpatients annually, where the average length of stay is 3.3 days (Hunter et al. 2014). For this study, we have chosen the broader boundaries of "all activities required to provide care in a high- and low-resource intensity inpatient unit" rather than specifying treatment of a specific condition, such as an earlier study of ICU treatment for septic shock (McGain et al. 2018). We are following inpatient LCA guidelines established in the United Kingdom (UK), in order to compare differences between these two contexts. Given the magnitude of this form of medical care, we believe there are many scalable opportunities to optimize inpatient care areas, maximize the efficient use of resources, and reduce the environmental and public health footprint of care (Kim et al. 2006). This study quantifies the resource-use, solid waste generation, and life cycle GHGs of inpatient stays in regular inpatient units/acute care ("low intensity") units and intensive care units (ICU or "high intensity") in a hospital in the northeastern US.

\section{Methods}

This study follows the UK NHS' (National Health Services) life cycle assessment (LCA)-based guideline to quantify solid waste generation and GHGs of a high and low intensity inpatient unit (Penny et al. 2015). LCA is a tool used to quantify the environmental emissions of a product or process throughout its life cycle - from raw material extraction, through production, use, and disposal. The International Organization for Standardization (ISO 14040) (International Organization for Standardization 2006) specifies 4 steps for LCA: (1) goal and scope definition, (2) life cycle inventory analysis (LCI), (3) life cycle impact assessment, and (4) interpretation analyses. LCA can be conducted in relation to physical flows, a "process LCA" approach. Where physical relationships are unknown, monetary flows and economic expenditures between economic sectors are used to estimate emissions (economic input output LCA or EIOLCA). A "hybrid LCA" combines both approaches, using EIOLCA models to estimate emissions based on the cost of a material (emissions per \$) and process-based LCI databases to estimate emissions of specific quantities of materials (emissions per kilogram). This study uses an augmented process-based hybrid LCA approach to estimate GHGs from a regular medical inpatient unit and a medical intensive care unit at a US hospital (Bilec 2007; Thiel et al. 2014; Guggemos 2003). It should be noted that LCA studies will produce different results depending on the modeling approach; as such, we limit detailed comparisons to the UK, due to similar methodology. 
This study seeks to inform resource conservation and environmentally-friendly strategies for hospital policymakers, administrators, and clinicians. An average estimate of solid waste and GHGs per bed day gives a baseline from which more detailed studies by treatment pathway can be conducted, and it identifies opportunities that can lead, broadly, to optimized resource use regardless of specific therapies employed in a unit.

\subsection{Case location}

NYU Langone Hospital-Brooklyn is a 543,659 $\mathrm{ft}^{2}, 450$ bed private hospital (Hospital). This location was chosen because it represents a typical US hospital, and hospital staff and administrators were willing to share data on energy use, patient throughput, and resource use. The low intensity, acute inpatient unit serves adults with medical, surgical, and cardiac diagnoses, including patients that require telemetry monitoring, post cutaneous interventions, or patients needing to be weaned from a ventilator. This acute unit has 23 double occupancy rooms and 3 single rooms and occupies $9106 \mathrm{sf}$. The intensive care unit (ICU) serves adults with complex medical conditions requiring specialized critical care, including respiratory failure, pneumonia, ARDS, and heart, renal, and liver failure. This ICU has 12 single occupancy rooms and occupies 1862 sf. See Table 1 for more information on each unit.

This study was deemed non-human subjects research and did not require ethics board approval.

\subsection{Study scope and boundaries}

This study assesses resource use, solid waste generation, and GHGs of an acute unit and ICU. The functional unit for the life cycle GHG calculations is 1 year of inpatient care in both a high- and low-intensity unit. We also utilize the unit of "bed day", a measure of occupancy based on number of beds and days they were in use.

The boundaries of this study (Fig. 1) include production and disposal of all physical resources (disposable and reusable supplies, medical gases, pharmaceuticals, capital equipment) and the consumption of energy (for lighting; plug loads and equipment usage; heating, ventilation, and air conditioning (HVAC); and water pumping) used in each unit over a 1-year period (Table 2). Emissions from staff commuting and an estimate of food service activities for inpatients (not staff) are also included.

This study does not include the building infrastructure (e.g., construction or maintenance of water delivery, HVAC, and lighting systems), transportation of patients to and from the hospital, or supporting activities such as administrative or financial services. It does not include the impact of laboratory tests ordered from the inpatient units (though it would include any materials used for sampling that were billed to the units or disposed of within the units). It also does not include production of cleaning chemicals or supplies as these are purchased through a hospital-wide department rather than these particular units, though this study does account for the solid waste treatment from any cleaning products disposed of within the units.

\subsection{Data collection}

Primary methods of data collection used in this study were as follows: site observations, hospital records, and manual waste audits. Data from hospital records was collected retrospectively, using Calendar Year 2017 (CY17) for total hospital solid waste and medical gas data and fiscal year (FY17, from September 2016 through August 2017) for all other data.

\subsubsection{Observations}

Three members of the research team spent 3 months in the inpatient units, examining unit layout, capital equipment (computer screens/monitors, EEG machines, etc.), stocking practices, flow of materials, room turnover protocols, and solid waste disposal. Interviews were conducted with the staff to more clearly understand how solid waste was generated and how the space was being utilized. The faceto-face interactions helped create mutual understanding and
Table 1 Demographic information for the units selected at the case location

\begin{tabular}{|c|c|c|}
\hline & Acute unit (low intensity) & ICU (high intensity) \\
\hline Number of beds & 49 & 12 \\
\hline Number of patient rooms & $\begin{array}{l}26 \text { ( } 23 \text { double occupancy } \\
\text { and } 3 \text { single) }\end{array}$ & 12 (single occupancy rooms) \\
\hline Total area (square feet) & 9106 & 1862 \\
\hline Average length of stay (days) & 4.55 & 4.64 \\
\hline Total bed days per year & 14,427 & 2536 \\
\hline Full time employees & 96.2 & 35.8 \\
\hline Worked nursing hours per year & 177,082 & 56,787 \\
\hline
\end{tabular}




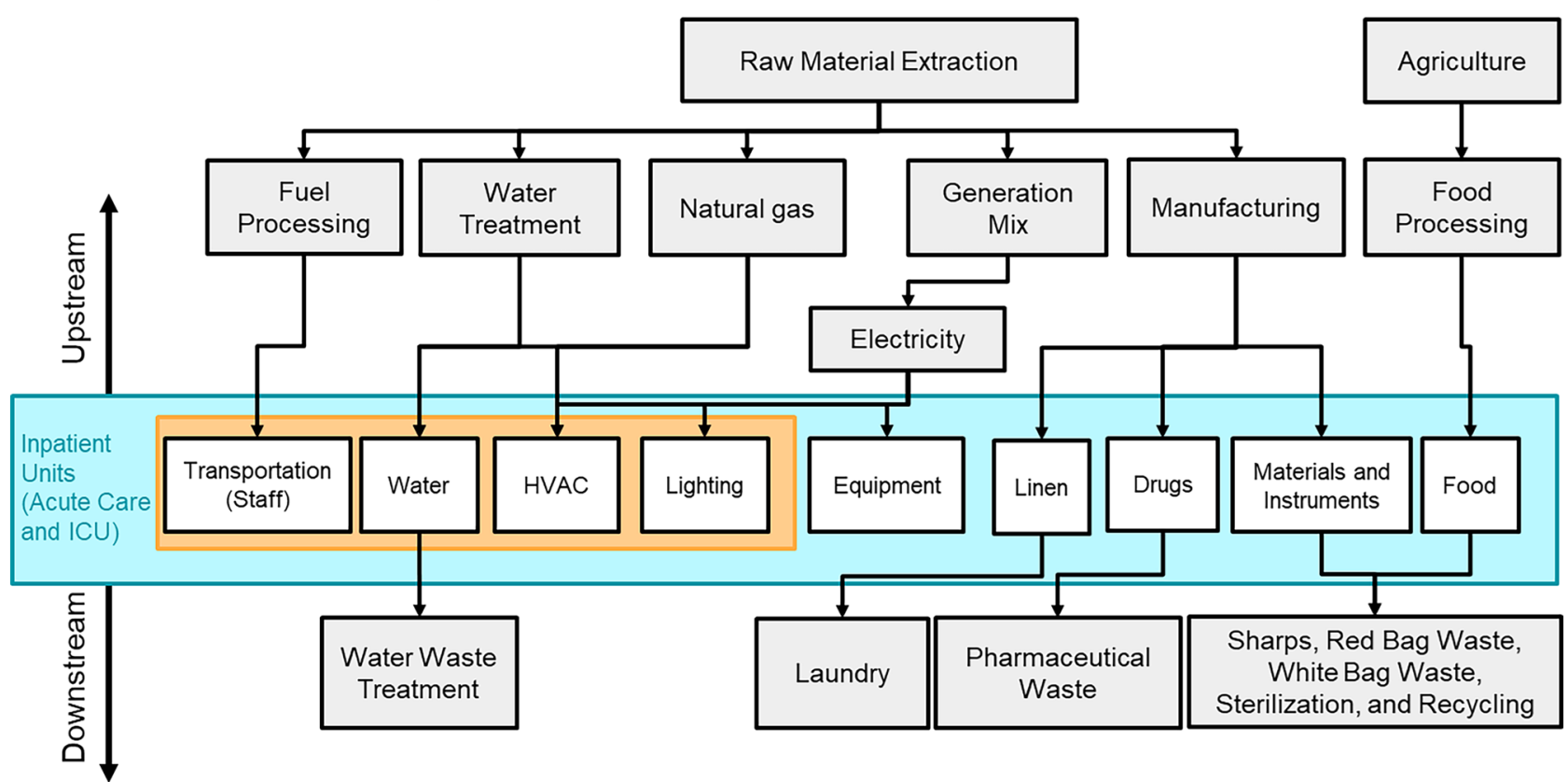

Fig. 1 Study boundaries for both an acute care (low intensity) and an intensive care (ICU or high intensity) inpatient unit in the USA

enthusiasm for the goals and objectives of the study. They also helped with identifying what should and should not be included in the scope of the study and introduced our project to the unit staff.

\subsubsection{Utility data, energy, and medical gas data}

Utility records were collected from the hospital's Facility Management team, and included the use of electricity, natural gas, water, and fuel oil for the hospital over the fiscal year. These datasets are not specific to any particular department within the hospital (utilities are not sub-metered), and thus, these data had to be allocated to our study units, as described in the " 2 ". Medical gases (oxygen and nitrous oxide, for which there are wall-ports and canisters in each unit) were also similarly allocated to each unit.

\subsubsection{Capital equipment, disposable supply, pharmaceutical, and linen data}

Capital equipment, such as computers, monitors, printers, defibrillators, medication dispensers, warming units, patient beds, nursing stations, and portable ultrasound machines, are occasionally purchased by a hospital and used over a period of years. To account for the production of these items, this study assumes that the quantity of items purchased in FY17 is a standard (or average) yearly cost for replacing or maintaining current capital goods. One modification was made specifically to the purchase of defibrillators in the acute unit, as there was a mass replacement of defibrillators during the study period. We, therefore, allocated the purchase price of these defibrillators over an estimated lifespan of 8 years. Of note, this approach does not account for the production

Table 2 Study scope and boundaries, * for 1-year period, September 2016 through August 2017, ** any materials used for sampling that were billed to the unit or disposed of within the unit would be included in the study

\begin{tabular}{ll}
\hline Study includes & Study does not include \\
\hline $\begin{array}{l}\text { Physical resources for each unit (disposable and reusable supplies and equipment, } \\
\text { medical gases, pharmaceuticals, solid waste treatment)* }\end{array}$ & $\begin{array}{c}\text { Building infrastructure (construction or maintenance of water } \\
\text { delivery, HVAC, and lighting systems) }\end{array}$ \\
$\begin{array}{l}\text { Energy for each unit (lighting; equipment usage; heating, ventilation, and air } \\
\text { conditioning (HVAC))* }\end{array}$ & $\begin{array}{c}\text { Transportation of patients to and from the hospital } \\
\text { Emissions from staff commuting }\end{array}$ \\
$\begin{array}{ll}\text { Estimate of food service activities for inpatients } \\
\text { Water provision and wastewater treatment }\end{array}$ & $\begin{array}{l}\text { Impact of laboratory tests ordered from inpatient units** } \\
\text { Production of cleaning chemicals and supplies }\end{array}$ \\
\hline
\end{tabular}


of capital goods purchased prior to this year, but instead assumes the "maintenance costs" of purchasing new equipment is similar from year to year.

An itemized list of disposable supplies and their costs from FY17 was obtained from the hospital's Finance Department. The number and cost of pharmaceuticals distributed within each unit were collected from the hospital's Pharmacy.

Reusable linens are rented from a third-party vendor who is also responsible for laundering. The hospital's Linens Department provided data on the quantity of linens delivered to the acute care unit and ICU and the total cost of linen rental, which includes laundering and delivery to and from the units, 7 days a week.

\subsubsection{Food services}

The Food Services Department was unable to provide a detailed record of meals served to the units over a calendar year. Therefore, we assumed each patient was issued a solid meal tray three times daily and based GHG estimates on the cost of the meal service. Obviously, some patients will be unable to consume solid foods; however, this assumption allows us to assess the relative potential impact of food services in each unit, which can be further analyzed in future studies (Collins 2020; Thiel et al. 2021).

\subsubsection{Staff commuting data and assumptions}

Commuting estimates have become more common in LCAs and GHG reporting of healthcare activities, as studies have shown large portions of a procedure's emissions are the result of commuting by patients and staff to those procedures, and a large share of commuting is due to healthcare activities (Duane et al. 2019; Wootton et al. 2010; Morris et al. 2013; Wang et al. 2021). Given the recent surge in telemedicine, there is further incentive to assess the impact of commuting and transportation, to better understand the potential impact of new remote-access technologies (Mann et al. 2020). For this case location, we estimated commuting of staff using staffing levels (number of employees) in both units, collected from the Human Resources Department. Average working days for each employee were estimated at 240 days per year. Commuting distances and modes of transit were based on data from the most recent New York City-sponsored Peripheral Travel Study (Planning 2010).

\subsubsection{Waste audits}

The hospital's Sustainability Manager and Building Services Department, which manages the hospital's waste removal, provided data on the total amount of solid waste the hospital produces annually. However, there were no unit-specific waste generation data. We conducted manual audits of the solid waste streams, as done in previous healthcare studies (Thiel et al. 2014; Tieszen and Gruenberg 1992; Namburar et al. 2018; McGain et al. 2009; Furukawa et al. 2016; Hames 2013; Kubicki et al. 2015).

We audited five types of solid waste from each unit: (1) regulated medical waste (RMW), also colloquially known as red bag waste or hazardous medical waste, (2) recycling waste, which is largely cardboard packaging, (3) white bag/ conventional municipal solid waste, (4) non-RCRA (Resource Conservation and Recovery Act) hazardous pharmaceutical waste including carcinogenic or endocrine-disrupting drugs, and (5) sharps waste. The waste from both units was audited for a period of 5 days, Monday through Friday from 8 A.M. to 8 P.M., the active period of waste removal. Waste was intercepted during removal from each unit, and each bag was weighed using an Edlund ERS-60 scale $(30 \pm 0.005 \mathrm{~kg})$. Trash bags were not opened nor sorted into sub-categories. The waste was allocated per bed day for the two units, based on the number of bed days during the audit period.

\subsection{Life cycle assessment}

\subsubsection{Process LCA data: utility consumption, medical gases, waste treatment, and staff travel}

The GHGs from each unit's electricity were estimated using New York emission factors from the US Environmental Protection Agency's (EPA) Emissions and Generation Resource Integrated Database (eGRID2016 v8.0) (US EPA 2018a). GHGs from natural gas, fuel oil, and water consumption; the manufacturing and delivery of medical gases; solid waste disposal via landfilling; and staff commuting were calculated using Ecoinvent 3.4 unit process database (Weidema et al. 2013; Moreno et al. 2011) through the software Simapro 8.5.2.0 (PRé Consultants 2018). A list of specific unit processes can be found in Supplemental Information Table 1.

\subsubsection{EIOLCA data: supply production, food and laundry services}

Emissions from the production of disposable supplies, allocated capital equipment production, food production, and linen production and laundering were estimated using the 2013 US Environmentally Extended Input Output (EEIO) LCA model v1.1 in OpenLCA v1.10.3 (Yang et al. 2017; Hildenbrand and Ciroth 2019). A list of specific economic sectors used can be found in Supplemental Information Table 1. Using a nationwide average factor of 0.78 , the dollar value of these items was deflated from 2017 to 2002 US dollars (Group 2018). 


\subsection{Impact assessment method}

All greenhouse gas emissions were estimated using the IPCC Fifth Assessment Report, AR5 (IPCC GWP 100a) in Simapro 8.5.2.0 (PRé Consultants 2018; Intergovernmental Panel on Climate Change 2016). This estimates the 100 -year time horizon global warming potentials of various substances relative to $\mathrm{CO}_{2}$, thus results are presented in kilograms of carbon dioxide equivalents, or $\mathrm{kg} \mathrm{CO}_{2}$-e.

\subsubsection{Sensitivity analyses: utility and medical gas allocations}

We allocated utility use (electricity, water, etc.) and medical gases by both floor area and staffing levels. The floor area approach is standard within the building industry but may fail to capture the relative intensity of energy use in specific hospital spaces like labs, operating rooms, and ICUs (for example surgical ORs can consume up to $4.5 \times$ more per square foot than other spaces in the hospital (MacNeill et al. 2017)). Here, we have removed non-clinical spaces (such as hallways and elevators) from the total hospital floor area and each unit's floor area and allocated without any additional intensity factors, as per the UK guidance (Penny et al. 2015). Of the 343,659 total sf, of the hospital, 274,426 sf were designated for clinical activities. The acute care unit occupies $4 \%$ of this hospital's clinical spaces, while the ICU occupies $0.68 \%$. The UK-based study allocated hospital energy consumption calculations by staffing levels, as staffing intensity is likely to mirror energy intensity (Penny et al. 2015). Of the hospital's 3507 fulltime employees, 96.2 $(2.7 \%)$ work in the acute care unit and $35.8(1.02 \%)$ work in the ICU. Results for this study are reported for both allocation methods.

\section{Results}

\subsection{Waste audit}

The acute care unit generated between 84 and $111 \mathrm{~kg}$ of solid waste daily. This results in about $6 \mathrm{~kg}$ of solid waste per bed day, or $79,685 \mathrm{~kg}$ of solid waste annually. This is about $5 \%$ of the hospital's total annual solid waste generation (Tables 3 and 4). The ICU generated between 25 and $81 \mathrm{~kg}$ of solid waste daily. This results in about $7 \mathrm{~kg}$ of solid waste per bed day, for an annual total of $18,098 \mathrm{~kg}$ of solid waste, or about $1 \%$ of the hospital's total waste. The acute care unit produced the largest portion of the hospital's Non-RCRA Hazardous Pharmaceutical Wastes (at $743 \mathrm{~kg}$ or $15 \%$ of the annual total) while the ICU generated $533 \mathrm{~kg}$ (or $11 \%$ of the hospital's annual total). The acute care unit also produced over $4650 \mathrm{~kg}$ of sharps waste per year (16\% of the hospital's total), while the ICU produced $1240 \mathrm{~kg}$ (or $4.4 \%)$.

\subsection{Resource consumption}

\subsubsection{Energy and water use}

The whole hospital consumes nearly 21 million $\mathrm{kWh}$ of electricity per year, 63 million MJ of natural gas, and over $454,000 \mathrm{~L}$ of fuel oil. The hospital also uses over $177,000 \mathrm{~m}^{3}$ of water each year. The acute care unit is estimated to consume $4.0 \%$ of the hospital total over the course of the year when allocated by floor area and $2.7 \%$ of the hospital total when allocated by relative staffing intensity of the space. By the staffing allocation, this results in approximately 40 kWh electricity, $122 \mathrm{MJ}$ natural gas, $0.9 \mathrm{~L}$ of fuel oil, and 0.3 $\mathrm{m}^{3}$ of water per bed day (Table 4). The ICU is estimated to consume $0.7 \%$ of the annual hospital total when allocated by floor area and $1.0 \%$ of the hospital total by relative staffing intensity. By the staffing allocation, this results in approximately $84 \mathrm{kWh}$ electricity, $258 \mathrm{MJ}$ natural gas, $1.9 \mathrm{~L}$ of fuel oil, and $0.7 \mathrm{~m}^{3}$ of water per bed day.

\subsubsection{Supplies and equipment}

Over the course of the year, the acute care unit spent approximately $\$ 57 /$ bed day on consumable supplies and equipment. A majority of spending on consumables came from medical supplies (\$31/bed day) including ECG leads, pulse oximeters, patient gowns, catheters, suction equipment, and gloves. About $\$ 20 /$ bed day was spent on capital equipment, including beds and defibrillators. In the ICU, yearly spending on supplies and equipment totaled approximately $\$ 263 /$ bed day. Capital equipment purchases and rentals made up about \$90/ bed day of that total, a majority for beds and patient positioning equipment. Consumable supply purchases were largely made up of medical supplies (\$121/bed day) including pulse oximeters, catheterization kits, central line supplies, suction systems, needle guides, and ECG leads.

\subsubsection{Life cycle greenhouse gas emissions}

The acute care unit generates an estimated $45 \mathrm{~kg} \mathrm{CO}_{2}$-e per bed day based on staff allocation (Table 4). A majority of the acute care unit's GHGs (48-56\% depending on allocation method) come from overall energy usage including electricity, natural gas, and fuel oil; food services (25-30\%), and consumables such as disposable medical supply production (22-26\%). Note that these relative impacts were similar for both allocation methods. However, the floor area allocation results in a larger quantity of GHGs than the staff allocation method, for an estimated total of $55 \mathrm{~kg} \mathrm{CO}_{2}$-e emitted per bed day. 
Table 3 Waste generation. * Includes only the hospital waste types that are generated in studied inpatient units, ** has 12 beds ( 1 bed per room), *** has 49 beds ( 23 rooms with 2 beds each and 3 single rooms)

\begin{tabular}{|c|c|c|c|c|c|}
\hline & Whole hospital* (kg) & $\begin{array}{l}\text { Acute care unit, estimated } \\
\text { annual, } \mathrm{kg}(\% \text { of hospital } \\
\text { total) }\end{array}$ & $\begin{array}{l}\text { ICU, estimated annual, } \\
\text { kg (\% of hospital total) }\end{array}$ & $\begin{array}{l}\text { ICU** } \\
\text { (kg/bed } \\
\text { day) }\end{array}$ & $\begin{array}{l}\text { Acute care } \\
\text { unit***(kg/per } \\
\text { day })\end{array}$ \\
\hline Red bag waste (kg) & $167,883.6$ & $7029.3(4.19 \%)$ & $246.4(0.15 \%)$ & 0.1 & 0.5 \\
\hline Recycling (kg) & $316,906.8$ & $0.0(0.00 \%)$ & $322.4(0.10 \%)$ & 0.1 & 0.0 \\
\hline White bag waste $(\mathrm{kg})$ & $1,221,978$ & $67,260.1(5.50 \%)$ & $15,755.4(1.29 \%)$ & 6.2 & 4.7 \\
\hline $\begin{array}{l}\text { Non-RCRA hazardous } \\
\text { pharmaceutical waste } \\
(\mathrm{kg})\end{array}$ & 4940.53 & $743.1(15.04 \%)$ & $533.0(10.79 \%)$ & 0.2 & 0.1 \\
\hline Sharps (kg) & $28,367.67$ & $4652.3(16.40 \%)$ & $1240.8(4.37 \%)$ & 0.5 & 0.3 \\
\hline Total & $1,740,076.6$ & $79,684.7(4.58 \%)$ & $18,097.98(1.04 \%)$ & 7.1 & 5.5 \\
\hline
\end{tabular}

The ICU generates an estimated $138 \mathrm{~kg} \mathrm{CO}_{2}$-e per bed day (staff allocation). The highest contributions to the ICU's GHGs come from procurement of consumables (32-37\%), procurement of equipment (28-32\%), and energy usage (25-33\% depending on allocation method). In the case of the ICU, floor area allocation decreases the GHG emission estimates for energy, water, and medical gases, resulting in a total GHG emission estimate of $121 \mathrm{~kg} \mathrm{CO}_{2}$-e per bed day.

For both units, the medical consumables with highest expenditures (and, therefore, highest proportion of GHGs from their production) include catheterization kits, pulse oximeters, electrocardiogram kits, gloves, syringes, suction canisters, and gowns. Of note, the structure of EIOLCA models limits our ability to compare items within the same economic sector, as the carbon emissions are estimated from the average spend across the whole sector. To identify which specific consumables contribute more to carbon emissions, future studies should use actual physical flows (process LCA).

\section{Discussion}

Over 1 year, this site generates an estimated $656,000 \mathrm{~kg}$ of $\mathrm{CO}_{2}-\mathrm{e}$ and $80,000 \mathrm{~kg}$ of solid waste from acute care, and an estimated $349,000 \mathrm{~kg}$ of $\mathrm{CO}_{2}$-e and $18,100 \mathrm{~kg}$ of solid waste each year from intensive care. This is equivalent to the GHG emissions from 139 passenger vehicles and 74 passenger vehicles driven for 1 year, respectively (US EPA 2018b).

Literature on waste generation in inpatient units is sparse; however, two studies from medical ICUs in Australia measured 505 and $540 \mathrm{~kg}$ of solid waste production over a 1 week

Table 4 Greenhouse gas (GHG) emissions from low intensity or regular inpatient unit (Acute Care Unit) and high intensity unit (ICU); *denotes those data inputs that were allocated using either a floor area allocation or a staff intensity allocation

\begin{tabular}{|c|c|c|c|c|}
\hline $\begin{array}{l}\mathrm{GHG} \text { emissions per bed day }(\mathrm{kg} \\
\left.\mathrm{CO}_{2}-\mathrm{e}\right)\end{array}$ & $\begin{array}{l}\text { Acute care unit (floor } \\
\text { area allocation) }\end{array}$ & $\begin{array}{l}\text { Acute care unit } \\
\text { (staff allocation) }\end{array}$ & ICU (floor area allocation) & ICU (staff allocation) \\
\hline Energy* & 30.8 & 21.6 & 30.5 & 45.8 \\
\hline Water* & 0.3 & 0.2 & 0.3 & 0.4 \\
\hline Waste & 3.4 & 3.4 & 4.3 & 4.3 \\
\hline Consumables & 12.0 & 12.0 & 44.4 & 44.4 \\
\hline Medical gases* & 2.4 & 1.7 & 2.4 & 3.6 \\
\hline Equipment & 6.5 & 6.5 & 38.9 & 38.9 \\
\hline Food & 13.8 & 13.8 & 13.8 & 13.8 \\
\hline Staff travel & 4.9 & 4.9 & 10.4 & 10.4 \\
\hline Total $\mathrm{CO}_{2}-\mathrm{e}$ & 55.4 & 45.5 & 120.8 & 137.5 \\
\hline Resource use per bed day & $\begin{array}{l}\text { Acute care unit (floor } \\
\text { area allocation) }\end{array}$ & $\begin{array}{l}\text { Acute care unit } \\
\text { (staff allocation) }\end{array}$ & ICU (floor area allocation) & ICU (staff allocation) \\
\hline Water direct total, $\mathrm{m}^{3 *}$ & 0.5 & 0.3 & 0.5 & 0.7 \\
\hline Waste total, $\mathrm{kg}$ & 5.5 & 5.5 & 7.1 & 7.1 \\
\hline Hazardous waste, $\mathrm{kg}$ & 0.9 & 0.9 & 0.8 & 0.8 \\
\hline Non-hazardous waste, $\mathrm{kg}$ & 4.7 & 4.7 & 6.3 & 6.3 \\
\hline
\end{tabular}


period for 10 and 11 beds, respectively, (Kubicki et al. 2015; McGain et al. 2009) compared to the $200 \mathrm{~kg}$ generated over a 5-day period in our 12-bed ICU. One study stated that this was about $5 \%$ of the hospital's total solid waste generation (McGain et al. 2009). Both studies found substantial opportunities for recycling, estimating that $28-57 \%$ of total waste was potentially recyclable. Waste education and increased signage helped decreased sharps waste in a Melbourne, Australia-based ICU (Hames 2013). A study of an ICU in Sao Paulo, Brazil tested solid waste reduction interventions such as redesigning pharmaceutical doses and packaging, installing waste containers for non-recyclables and chemical wastes, and educating staff. These interventions reduced their solid waste generation from $13.7 \mathrm{~kg} /$ patient/day to $8.4 \mathrm{~kg} /$ patient/day (Furukawa et al. 2016). A recent study in a US-based pediatric ICU measured $76 \mathrm{~kg}$ of unused items over a 3-week period, largely endotracheal tubes, diapers, underpads, and flexible suction catheters (Ghersin et al. 2020). The UK-based study reported solid waste generation of $3.3 \mathrm{~kg} / \mathrm{bed}$ day in the low intensity, acute care unit (about $60 \%$ of the US's waste generation) and $13.2 \mathrm{~kg}$ of solid waste in the high intensity ICU ( $180 \%$ of the US's generation) (Penny et al. 2015). There are no standardized reporting methods for medical waste audits, so it is difficult to compare the occupancy or resource-intensity of these previous studies with our current study; however, it is clear that there are many opportunities to reduce resource consumption in inpatient units.

For GHG emissions, the results of our study are comparable to the previous UK-based study of low- and highintensity inpatient stays (Fig. 2). For low intensity, acute care inpatient stays, the UK's GHG emissions are $25 \%$ less than the US (staff allocation). The UK's GHGs for high intensity ICU stays were $39 \%$ less than the US. For both types of inpatient stay, the US location generates considerably more GHGs than the UK in the categories of equipment (4 to 10 times more). Equipment purchases in our study included a few beds, scales, reusable cushions, and patient lifts. Differences could signify larger spending on capital goods in the US or larger-than-normal spending on equipment during the study period, though the UK also has been actively decarbonizing their electric grid which could decrease their emission intensity. Emissions from solid waste treatment are also higher 2 to 6 times more) in the US.

The results for the ICU are also comparable to a previous study of GHGs from treating septic shock patients in an intensive care in the US and Australia. For US locations in the septic shock study, the total carbon footprint was about $178 \mathrm{~kg} \mathrm{CO}_{2}$-e per day (McGain et al. 2018), which is 1.3 times more than the $138 \mathrm{~kg} \mathrm{CO}_{2}$-e found in this study with staff allocation. US septic shock patients were estimated to generate $3.4 \mathrm{~kg}$ of single-use materials daily, versus the total

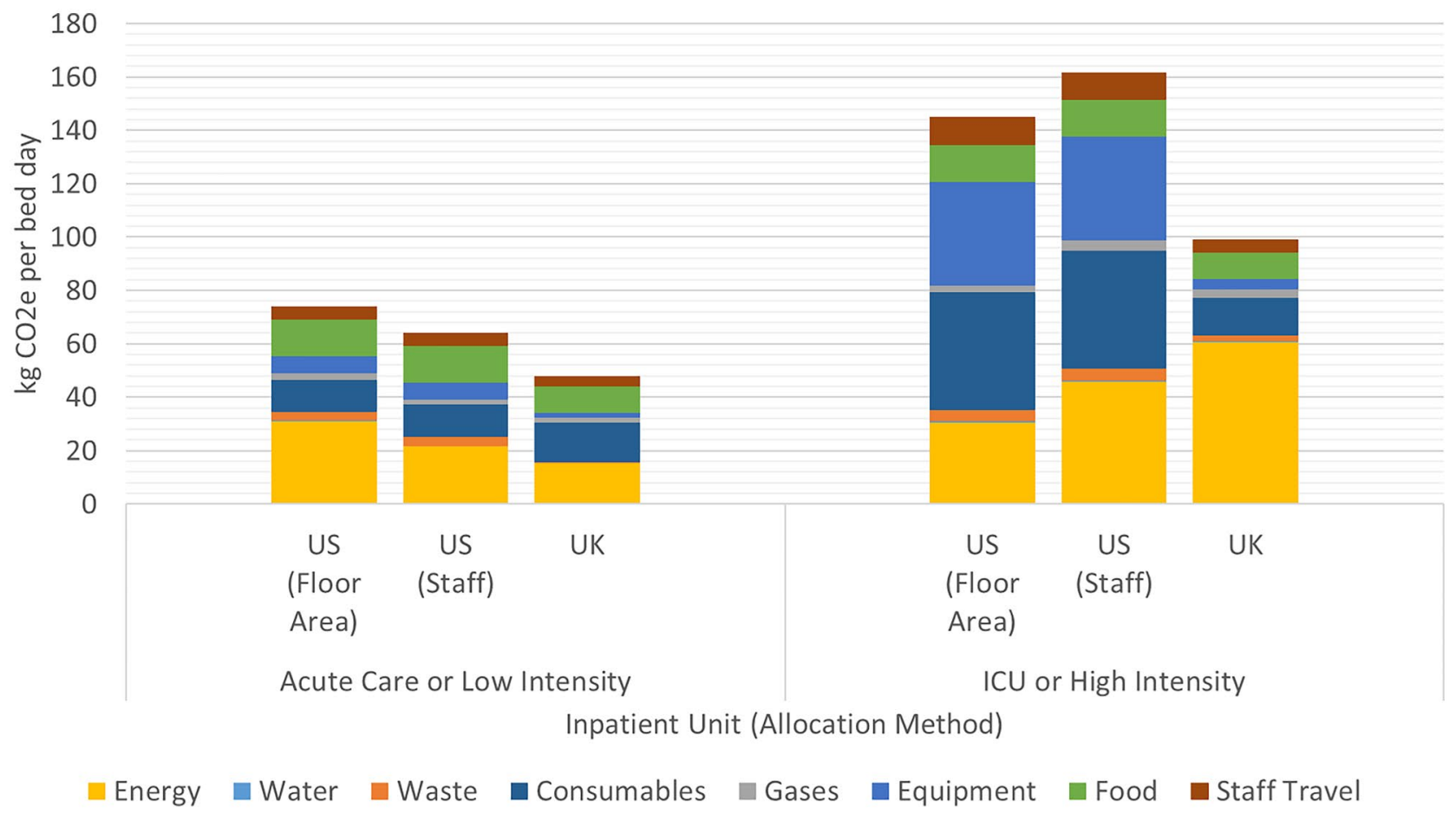

Fig. 2 Greenhouse gas emissions from an acute care (low intensity) and an intensive care (ICU or high intensity) inpatient unit in the USA and UK; note: the original UK study combined food and consumables; "staff" and "floor area " denote allocation techniques 
solid waste measured here at $7.1 \mathrm{~kg}$. Differences between studies may be due to focus on a single patient diagnosis and variation in medical practice. Septic shock commonly requires medical treatments such as mechanical ventilation and renal support that often have higher energy demand (McGain et al. 2018), and though some patients in our studied units would be receiving this type of care, our patients represent a mix of medical needs. Though both studies use similar hybrid approaches, the septic shock study includes pathology costs (in an EIO model), used a process-LCA approach for consumables, directly audited plug loads, and modeled HVAC energy demand (rather than using an energy allocation approach). This difference in boundaries and approaches will impact results. For example, in their inpatient ICU, the septic shock study estimates electricity use at $124 \mathrm{kWh} /$ patient/day (1.5 times more than our study) and natural gas at $0.53 \mathrm{GJ} /$ patient/day (2 times more).

\subsection{Decarbonizing care and reducing waste}

First and foremost, reducing the number of patients in inpatient care, and especially ICU care, would have the largest potential to reduce emissions, with co-benefits of better health and reduced spending for the general population. Investment in public health, environmental protections, and primary care have the potential to reduce inpatient admissions at a population level by addressing health and safety needs of patients before they become acute. Unnecessary admissions can be avoided through a variety of approaches depending on the location from which a patient is being transferred and admitted to a hospital (Ouslander et al. 2016; Freund et al. 2013). Movements such as 'Choosing Wisely' campaign and 'Getting It Right First Time' highlight the importance of correct procedures, on the correct patients, at the correct time. They seek to reduce both unnecessary testing and procedures, and complications or errors that result in additional hospitalizations or medical interventions (Levinson et al. 2018, 2015; Malhotra et al. 2016; Wolfson et al. 2014; Cassel and Guest 2012).

Inpatient care will still be necessary, and the results of this study point to possible target areas for GHG reduction in inpatient care areas. For both acute care and ICUs, a majority of emissions originate in energy use and the purchase of capital equipment and supplies. Therefore, we focus our discussion on these topics, generically, and the ways in which the industry is addressing these issues.

For reducing emissions from energy, medical facilities should focus on de-carbonizing their energy sources, introducing energy reduction processes, and conducting energy efficiency upgrades to lighting, ventilation, and equipment. When renovating or building new inpatient spaces, energy efficiency, HVAC occupancy setbacks, and renewable energy sources should be prioritized (Teke and Timur 2014; Johnson 2010; Campion et al. 2016). Where possible, hospitals should procure energy-efficient capital equipment and supplies from manufacturers. Some products may have environmental product declarations (EPDs) to help guide more environmentally minded purchases.

Given GHGs from the production of consumables in both units, hospital administrators and clinicians should focus efforts on optimizing supply use. Reducing unnecessary items could reduce spending and improve footprint (Zygourakis et al. 2016; Thiel et al. 2018). During the study period, we observed many unopened, unused items thrown away during room turnovers. Cleaning and setup protocols should aim to minimize the amount of unnecessary waste in the inpatient space. Any pre-packaged disposable supply kits should be regularly reformulated to remove unnecessary items (Campion et al. 2015). Location of supply storage areas and waste receptacles can reduce accidental waste from employee's personal supply stashes leftover in pockets when shifts end. Additional savings could be gained through automated stocking systems (Moons et al. 2019). Prioritizing sustainable procurement practices (such as environmentally preferred purchasing) could reduce emissions associated with medical supplies and equipment (Chiarini et al. 2017; Rico and Oruezabala 2012).

Medical supply and device manufacturers should strive to create and market better, greener products (Sherman et al. 2019). Likewise, medical facilities and group purchasing organizations should ask for environmental performance data on products they regularly purchase and discard, or seek to utilize reusable supplies where possible (Thiel et al. 2020; Steyn et al. 2020; Thiel and Vukelich 2020). Medical facilities could also contract for commercial single use device (SUD) reprocessing to reduce GHGs from solid waste disposal (Unger and Landis 2016; DiConsiglio 2008). SUD reprocessing is an FDA-approved process where SUDs are sent to a third-party facility, cleaned, sterilized, and sold back to hospitals for less than the original purchase price. Our case study location currently uses SUD reprocessing on pulse oximeters and other devices, though this was not modeled in our study.

Specific interventions for emission reductions will depend on the circumstances within each individual inpatient unit. For example, in our study location, we modified standard room stocking protocols to reduce unnecessary waste of supplies. Specifically, suction containers will only be placed in a room where a patient condition is likely to need the use of suction, in-room storage is delineated between patient zones (from which all items need to be disposed) and non-patient zones, and in-room storage closets will be stocked in ways that prevent accidental dropping (and resulting disposal) of supplies. 


\subsection{Future research}

An exclusively process-LCA approach would enable a more detailed assessment of GHGs from each unit, particularly for consumable supplies and food; however, this requires more intensive data collection that may be more appropriate when studying specific therapies in inpatient spaces. The omission of certain elements of inpatient care, such as the production of cleaning chemicals and supply, will likely lead to an underestimate of the emissions of inpatient care in this study. Though their addition is expected to make only a small contribution to GHG emissions, cleaning chemicals may have greater influence in other impact categories and should be considered in future studies. In addition, our allocation assumptions could be tested and refined through sub-metering of clinical spaces, direct measurement of plug loads, or estimating plug loads of equipment through manufacturer power ratings. This approach would also enable better comparisons with the septic shock study and help differentiate the effect of LCA model design from actual clinical practice on emission estimates. This study was limited to a single hospital; replicating it with different hospitals and inpatient units could quantify variability in resource-use and identify best practices. Specific to this study, multiple waste audits conducted over the course of the year could help identify periodic fluctuations and other factors affecting solid waste generation. Qualitative studies could further identify sources of unnecessary supply waste and possible solutions. Furthermore, LCA results could be expanded beyond the GHGs reported here.

\section{Conclusion}

Understanding the source of emissions in a specific care pathway can help to put limited financial and human resources to effective use in reducing those emissions. This study presents a high-level analysis of the environmental footprint of inpatient stays in a large US hospital. With more cities and individuals pushing for carbon-free economies, more action needs to be taken by the healthcare sector to strategically reduce the overconsumption of resources and minimize the public health effects of healthcare services.

Supplementary Information The online version contains supplementary material available at https://doi.org/10.1007/s11367-021-01998-8.

Acknowledgements The views expressed in the submitted article are her or his own and not an official position of the institution or funder. Unrelated to this research, author CLT is a private consultant with the Stryker Corporation. The researchers would like to thank the staff and administrators at NYU Langone Health and NYU Langone Health Brooklyn Hospital, the NYU Tandon Summer Research Program, NYU Abu Dhabi, and Abdur "Mani" Rehman and Jagan Subramanian for their help with this research.
Funding This work was supported by a project grant from the Sustainable Healthcare Coalition (SHC).

Open Access This article is licensed under a Creative Commons Attribution 4.0 International License, which permits use, sharing, adaptation, distribution and reproduction in any medium or format, as long as you give appropriate credit to the original author(s) and the source, provide a link to the Creative Commons licence, and indicate if changes were made. The images or other third party material in this article are included in the article's Creative Commons licence, unless indicated otherwise in a credit line to the material. If material is not included in the article's Creative Commons licence and your intended use is not permitted by statutory regulation or exceeds the permitted use, you will need to obtain permission directly from the copyright holder. To view a copy of this licence, visit http://creativecommons.org/licenses/by/4.0/.

\section{References}

Andersen M, Sulbaek P, Nielsen OJ, Wallington TJ, Karpichev B, Sander SP (2012) Assessing the impact on global climate from general anesthetic gases. Anesth Analg May 114:1081-1085

Barraclough KA, Gleeson A, Holt SG, Agar JW (2017) The green dialysis survey: establishing a baseline for environmental sustainability across dialysis facilities in Victoria, Australia. Nephrology (Carlton)

Belkhir L, Elmeligi A (2019) Carbon footprint of the global pharmaceutical industry and relative impact of its major players. J Cleaner Prod 214:185-194

Berner JE, del Pilar MG, Troisi L, Chapman T, Vidal P (2017) Measuring the carbon footprint of plastic surgery: a preliminary experience in a Chilean teaching hospital, J Plast Reconstr Aesthet Surg

Berrang-Ford Lea, Sietsma AJ, Callaghan M, Minx JC, Scheelbeek PFD, Haddaway NR, Haines A, Dangour AD (2021) Systematic mapping of global research on climate and health: a machine learning review. Lancet Planet Health

Bilec M (2007) A hybrid life cycle assessment model for construction processes, 3284533. University of Pittsburgh

Campion N, Thiel CL, Focareta J, Bilec MM (2016) Understanding green building design and healthcare outcomes: evidence-based design analysis of an oncology unit. J Archit Eng 22:04016009

Campion N, Thiel CL, Woods NC, Swanzy L, Landis AE, Bilec MM (2015) Sustainable healthcare and environmental life-cycle impacts of disposable supplies: a focus on disposable custom packs. J Cleaner Prod 94:46-55

Campion N, Thiel CL, DeBlois J, Woods NC, Landis AE, Bilec MM (2012) Life cycle assessment perspectives on delivering an infant in the US. Sci Total Environ 425:191-198

Cassel CK, Guest JA (2012) Choosing Wisely: helping physicians and patients make smart decisions about their care. JAMA 307:1801-1802

Chen M, Zhou R, Du C, Meng F, Wang Y, Wu L, Yang X (2016) The carbon footprints of home and in-center peritoneal dialysis in China. Int Urol Nephrol 1-7:1-7

Chiarini A, Opoku A, Vagnoni E (2017) Public healthcare practices and criteria for a sustainable procurement: a comparative study between UK and Italy. J Cleaner Prod 162:391-399

Chua ALB, Amin R, Zhang J, Thiel CL, Gross JS (2021) The environmental impact of interventional radiology: an evaluation of greenhouse gas emissions from an academic interventional radiology practice. J Vasc Interv Radiol 32:907-15. e3

Cimprich A, Santillán-Saldivar J, Thiel CL, Sonnemann G, Young SB (2019) Potential for industrial ecology to support healthcare sustainability: scoping review of a fragmented literature 
and conceptual framework for future research. J Ind Ecology 23:1344-1352

CMS (2017) National health expenditures. In, edited by Centers for Medicare \& Medicaid Services - Office of the Actuary - National Health Statistics Group

Collins J (2020) Exploring strategies to improve the environmental sustainability of hospital foodservices

Connor A, Lillywhite R, Cooke MW (2011) The carbon footprints of home and in-center maintenance hemodialysis in the United Kingdom. Hemodial Int 1:39-51

Costello A, Montgomery H, Watts N (2013) Climate change: the challenge for healthcare professionals. BMJ 347

Development, Organization for Economic Cooperation (2019) Length of hospital stay. https://data.oecd.org/healthcare/lengthof-hospital-stay.htm

DiConsiglio J (2008) Reprocessing SUDs reduces waste, costs. Mater Manag Health Care 17:40-42

Duane B, Steinbach I, Ramasubbu D, Stancliffe R, Croasdale K, Harford S, Lomax R (2019) Environmental sustainability and travel within the dental practice. Br Dent J 226:525-530

Eckelman MJ, Sherman JD (2018) Estimated global disease burden from US health care sector greenhouse gas emissions. Am J Public Health 108:S120-S122

Eckelman M, Mosher M, Gonzalez A, Sherman J (2012) Comparative life cycle assessment of disposable and reusable laryngeal mask airways. Anesth Analg May 5:1067-72

Eckelman MJ, Huang K, Lagasse R, Senay E, Dubrow R, Sherman JD (2020) Health care pollution and public health damage in the United States: an update: study examines health care pollution and public health damage in the United States. Health Aff 39:2071-2079

Freund T, Campbell SM, Geissler S, Kunz CU, Mahler C, PetersKlimm F, Szecsenyi J (2013) Strategies for reducing potentially avoidable hospitalizations for ambulatory care-sensitive conditions. The Annals of Family Medicine 11:363-370

Furukawa P, de Oliveira I, Cunha CKO, da Luz M, Pedreira G, Marck PB (2016) Environmental sustainability in medication processes performed in hospital nursing care. Acta Paulista De Enfermagem 29:316-324

Ghersin ZJ, Flaherty MR, Yager P, Cummings BM (2020) Going green: decreasing medical waste in a paediatric intensive care unit in the United States. The New Bioethics 1-13

Goel H, Wemyss TA, Harris T, Steinbach I, Stancliffe R, CasselsBrown A, Thomas PBM, Thiel CL (2021) Improving productivity, costs and environmental impact in International Eye Health Services: using the 'Eyefficiency' cataract surgical services auditing tool to assess the value of cataract surgical services. BMJ Open Ophthalmol 6:e000642

Gordon IO, Sherman JD, Leapman M, Overcash M, Thiel CL (2021) Life cycle greenhouse gas emissions of gastrointestinal biopsies in a surgical pathology laboratory. Am J Clinic Pathol

Group Coin News Media (2018) US inflation calculator. https://www. usinflationcalculator.com/

Guggemos AA (2003) Environmental impacts of on-site construction processes: focus on structural frames. University of California, Berkeley, Ph.D.

Hames K (2013) Healthcare waste disposal: an analysis of the effect of education on improving waste disposal. Healthcare Infection 18:110-114

Hildenbrand JSM, Ciroth A (2019) OpenLCA modeling suite. In. GreenDelta

Holmner Å, Ebi KL, Lazuardi L, Nilsson M (2014) Carbon footprint of telemedicine solutions - unexplored opportunity for reducing carbon emissions in the health sector. PLoS One 9. Hospital, NYU Langone. NYU Langone Hospital-Brooklyn. https:// nyulangone.org/locations/nyu-langone-hospital-brooklyn
Hunter A, Johnson L, Coustasse A (2014) Reduction of intensive care unit length of stay: the case of early mobilization. Health Care Manag (frederick) 33:128-135

Intergovernmental Panel on Climate Change (2016) Global warming potential values. https://www.ghgprotocol.org/sites/default/ files/ghgp/Global-Warming-Potential-Values $\% 20 \% 28 \mathrm{Feb} \% 2016 \%$ 202016\%29_1.pdf

International Organization for Standardization (2006) ISO 14040. In Environmental management - life cycle assessment - principles and framework

Janson C, Henderson R, Löfdahl M, Hedberg M, Sharma R, Wilkinson AJK (2020) Carbon footprint impact of the choice of inhalers for asthma and COPD. Thorax 75:82-84

Johnson SW (2010) Summarizing green practices in US hospitals. Hosp Top 88:75-81

Karliner, Josh, Scott Slotterback, Richard Boyd, Ben Ashby, and Kristian Steele. 2019. Health care's climate footprint: how the health sector contributes to the global climate crisis and opportunities for action. In, 48. Healthcare without harm ARUP

Kim CS, Spahlinger DA, Kin JM, Billi JE (2006) Lean health care: what can hospitals learn from a world-class automaker? J Hosp Med 1:191-199

Kubicki MA, McGain F, O'Shea CJ, Bates S (2015) Auditing an intensive care unit recycling program. Crit Care Resusc 17:135-140

Levinson W, Born K, Wolfson D (2018) Choosing wisely campaigns: a work in progress. JAMA 319:1975-1976

Levinson W, Marjon Kallewaard R, Bhatia S, Wolfson D, Shortt S, Kerr EA (2015) Choosing Wisely: a growing international campaign. BMJ Qual Saf 24:167-174

Lim AEK, Perkins A, Agar JWM (2013) The carbon footprint of an Australian satellite haemodialysis unit. Aust Health Rev 3:369-374

MacNeill AJ, Lillywhite R, Brown CJ (2017) The impact of surgery on global climate: a carbon footprinting study of operating theatres in three health systems. Lancet Planet Health 1:e381-e388

Malhotra A, Maughan D, Ansell J, Lehman R, Henderson A, Gray M, Stephenson T, Bailey S (2016) Choosing Wisely in the UK: reducing the harms of too much medicine. Br J Sports Med 50:826-828

Mann DM, Chen J, Chunara R, Testa PA, and Oded Nov (2020) COVID-19 transforms health care through telemedicine: evidence from the field. J Am Med Informat Assoc

Martin M, Mohnke A, Lewis GM, Reed Dunnick N, Keoleian G, Maturen KE (2018) Environmental impacts of abdominal imaging: a pilot investigation. J Am Coll Radiol 15:1385-1393

McDermott K, Elixhauser A, Sun R (2017) Trends in hospital inpatient stays in the United States, 2005-2014. https://www.hcup-us.ahrq. gov/reports/statbriefs/sb225-Inpatient-US-Stays-Trends.jsp?utm_ source $=$ ahrq\&utm_medium $=$ en $1 \& u t m \_t e r m=\& u t m \_c o n t e n t=1 \&$ utm_campaign=ahrq_en7_5_2017

McGain F, Burnham JP, Lau R, Aye L, Kollef MH, McAlister S (2018) The carbon footprint of treating patients with septic shock in the intensive care unit. Crit Care Resusc 4:304-312

McGain F, Story D, Hendel S (2009) An audit of intensive care unit recyclable waste. Anaesthesia 64:1299-1302

Moons K, Waeyenbergh G, Pintelon L (2019) Measuring the logistics performance of internal hospital supply chains-a literature study. Omega 82:205-217

Moreno ER, Weidema PB, Bauer C, Nemecek T, Vadenbo OC, Wernet G (2011) Documentation of changes implemented in ecoinvent Data 3.0. Ecoinvent Report 5(v3), The ecoinvent Centre. http:// www.ecoinvent.org/database/

Morris DS, Wright T, Somner JEA, Connor A (2013) The carbon footprint of cataract surgery. Eye 495-501

Namburar S, Pillai M, Varghese G, Thiel C, Robin AL (2018) Waste generated during glaucoma surgery: a comparison of two global 
facilities. American Journal of Ophthalmology Case Reports 12:87-90

Ouslander JG, Naharci I, Engstrom G, Shutes J, Wolf DG, Alpert G, Rojido C, Tappen R, Newman D (2016) Root cause analyses of transfers of skilled nursing facility patients to acute hospitals: lessons learned for reducing unnecessary hospitalizations. J Am Med Dir Assoc 17:256-262

Piccoli GB, Mery D (2017) Sister earth, our common home: toward a sustainable, planet friendly approach to dialysis, a paradigm of high technology medicine. J Ren Nutr 27:478-484

Planning NYC Department of City (2010) Mode of transportation to work. in Peripheral Travel Study

Power NE, Silberstein JL, Ghoneim TP, Guillonneau B, Touijer KA (2012) Environmental impact of minimally invasive surgery in the United States: an estimate of the carbon dioxide footprint. J Endourol 26:1639-1644

PRé Consultants (2018) SimaPro v 8.5.2.0. In, LCA software. Amersfoort, Netherlands: PRé Consultants

Rico J-C, Oruezabala G (2012) Green supply management in the healthcare public sector: Stakes, practices, and perspectives. Int J Healthcare Mgmt 5:154-163

Salas RN, Maibach E, Pencheon D, Watts N, Frumkin H (2020) A pathway to net zero emissions for healthcare. BMJ 371:m3785

Sherman JD, MJ Eckelman MJ (2018) Life cycle assessment and costing methods for device procurement: comparing reusable and single-use disposable laryngoscopes. Anesth Analg

Sherman JD, MacNeill A, Thiel C (2019) Reducing pollution from the health care industry. JAMA 322:1043-1044

Sherman JD, Thiel C, MacNeill A, Eckelman MJ, Dubrow R, Hopf H, Lagasse R, Bialowitz J, Costello A, Forbes MG, Stancliffe R, Anastas P, Anderko L, Baratz M, Barna S, Bhatnagar U, Burnham J, Cai Y, Cassels-Brown A, Cimprich AFP, Cole H, CoronadoGarcia L, Duane B, Grisotti G, Hartwell A, Kumar V, Kurth A, Leapman M, Morris DS, Overcash M, Parvatker AG, Pencheon D, Pollard D, Robaire B, Rockne K, Sadler BL, Schenk B, Sethi T, Sussman LS, Thompson J, Twomey JM, Vermund SH, Vukelich D, Wasim N, Wilson D, Young SB, Zimmerman J, Bilec MM (2020) The green print: advancement of environmental sustainability in healthcare. Resour Conserv Recycl 161:104882

Sherman J, Le C, Lamers V, Eckelman M (2012) Life cycle greenhouse gas emissions of anesthetic drugs. Anesth Analg May 114:1086-90

Steyn A, Cassels-Brown A, Chang D, Hannah Faal R, Vedanthan RV, Thiel C (2020) Frugal innovation for global surgery: leveraging lessons from low- and middle-income countries to optimise resource use and promote value-based care. Bullet Royal College Surgeons England 102:198-200

Tauber J, Chinwuba I, Kleyn D, Rothschild M, Kahn J, Thiel CL (2019) Quantification of the cost and potential environmental effects of unused pharmaceutical products in cataract surgery. JAMA Ophthalmology 137:1156-1163

Teke A, Timur O (2014) Overview of energy savings and efficiency strategies at the hospitals. International Journal of Economics and Management Engineering 8:242-248

Thiel CL, Schehlein E, Ravilla T, Ravindran RD, Robin AL, Saeedi OJ, Venkatesh R (2017) Cataract surgery and environmental sustainability: waste and lifecycle assessment of phacoemulsification at a private healthcare facility. J Cataract Refract Surg 11:1391-1398

Thiel C, Horwitz LI (2019) Improving value in health care through comprehensive supply optimization'. JAMA 322:1451-1452
Thiel CL, Eckelman M, Guido R, Huddleston M, Landis AE, Sherman J, Shrake SO, Copley-Woods N, Bilec MM (2014) Environmental impacts of surgical procedures: life cycle assessment of hysterectomy in the United States. Environ Sci Technol 49:1779-1786

Thiel CL, Park SW, Musicus AA, Agins J, Gan J, Held J, Horrocks A, Bragg MA (2021) Waste generation and carbon emissions of a hospital kitchen in the US: Potential for waste diversion and carbon reductions. PLoS One 16:e0247616

Thiel CL, Sherman JD, Hopf HW (2020) Use of disposable perioperative jackets and surgical site infections. JAMA Surgery

Thiel CL, Woods NC, Bilec MM (2018) Strategies to reduce greenhouse gas emissions from laparoscopic surgery. Am J Public Health 108:S158-S164

Thiel C, Vukelich DJ (2020) An urgent call to reduce and reuse hospital supplies for stronger financial, environmental and clinical sustainability. Managed Healthcare Exec

Tieszen ME, Gruenberg JC (1992) A quantitative, qualitative, and critical assessment of surgical waste: Surgeons venture through the trash can. J Am Med Assoc 267:2765-2768

Penny T, Collins M, Whiting A, Aumônier S (2015) Inpatient bed day module. In Care pathways: guidance on appraising sustainability. Environ Res Manag

Unger SR, Landis AE (2014) Comparative life cycle assessment of reused versus disposable dental burs. Int J Life Cycle Assess 9:1623-1631

Unger S, Landis A (2016) Assessing the environmental, human health, and economic impacts of reprocessed medical devices in a Phoenix hospital's supply chain. J Cleaner Prod 112

US EPA (2018a) eGRID2016 Version 8.0. In.: US Environmental Protection Agency

US EPA (2018b) Greenhouse gas equivalencies calculator. https:// www.epa.gov/energy/greenhouse-gas-equivalencies-calculator

Wang EY, Zafar JE, Lawrence CM, Gavin LF, Mishra S, Boateng A, Thiel CL, Dubrow R, Sherman JD (2021) Environmental emissions reduction of a preoperative evaluation center utilizing telehealth screening and standardized preoperative testing guidelines. Resour Conserv Recycl 171:105652

Weidema BP, Bauer Ch, Hischier R. Mutel Ch, Nemecek T, Reinhard J, Vadenbo CO, Wernet G (2013) Overview and methodology, data quality guideline for the ecoinvent database version 3. In. St. Gallen: the ecoinvent centre

Wolfson D, Santa J, Slass L (2014) Engaging physicians and consumers in conversations about treatment overuse and waste: a short history of the choosing wisely campaign. Acad Med 89:990-995

Wootton R, Tait A, Croft A (2010) Environmental aspects of health care in the Grampian NHS region and the place of telehealth. J Telemed Telecare 16:215-220

Yang Yi, Ingwersen WW, Hawkins TR, Srocka M, Meyer DE (2017) USEEIO: a new and transparent United States environmentallyextended input-output model. J Cleaner Prod 158:308-318

Zygourakis, Corinna C, Seungwon Yoon, Victoria Valencia, Christy Boscardin, Christopher Moriates, Ralph Gonzales, and Michael T Lawton. 2016. Operating room waste: disposable supply utilization in neurosurgical procedures, J Neurosurg 1-6

Publisher's Note Springer Nature remains neutral with regard to jurisdictional claims in published maps and institutional affiliations. 